\title{
ETV6/RUNX1-positive childhood acute lymphoblastic leukemia in China: excellent prognosis with improved BFM protocol
}

\author{
Yu Wang, Hui-min Zeng ${ }^{*}$ (iD and Le-ping Zhang
}

\begin{abstract}
Background: In childhood B-precursor acute lymphoblastic leukemia (B-ALL), the ETV6/RUNX1 fusion transcript is considered to have an excellent outcome. However, few studies of children with ETV6/RUNX1-positive ALL from China have been conducted. It is largely unknown whether clinical outcomes for patients with this genotype and important factors that influence such outcomes are similar to those reported in other countries. Therefore, it is important to analyze the outcomes of children with ETV6/RUNX1-positive ALL treated at our institution with the aim of identifying significant prognostic variables in a Chinese population.

Methods: We studied the clinical characteristics and treatment outcomes for 77 pediatric patients diagnosed with ETV6/RUNX1-positive ALL between 2005 and 2015 at our institution.

Results: The 5-year event-free survival (EFS) and the disease-free survival (DFS) were reported to be $90 \% \pm$ $3 \%$ and $96 \% \pm 3 \%$ respectively. Two patients had a relapse at a median of 42 months from diagnosis and the 5 -year cumulative incidence of relapse was $2.1 \%$. Despite intensive chemotherapy or allogeneic hematopoietic cell transplantation, the 2 relapsed patients succumbed to the disease progression and the 5 -year overall survival (OS) was $97 \% \pm 2 \%$. Multivariate analysis for EFS revealed that the minimal residual disease (MRD) $\geq 10^{-3}$ on Day +33 negatively affected the outcome.

Conclusions: In conclusion, patients with ETV6/RUNX1 fusion transcript can achieve a high rate of complete remission and the long-term curative effect was excellent under risk-stratified treatment. In case of relapse, the MRD level at the end of induction therapy should be taken into consideration while deciding the appropriate chemotherapy dosage.
\end{abstract}

Keywords: Acute lymphoblastic leukemia, ETV6/RUNX1, MRD, Prognosis

\section{Background}

Acute lymphoblastic leukemia (ALL) can be exactly classified according to immunophenotype and molecular aberrations since several somatic genetic alterations have been characterized during the last decades $[1,2]$. In pediatric B-ALL, $\mathrm{t}(12 ; 21)$ (p13; q23) is the most common chromosomal abnormality [3]. It results from the juxtaposition of the transcription factor ETV6 gene on chromosome 12 to the RUNX1 sequences on chromosome 21 [3-6]. ETV6/RUNX1-positive ALL is considered to arise prenatally and may precede a pre-leukemic

\footnotetext{
* Correspondence: zengpretty@aliyun.com

Department of Pediatrics, Peking University People's Hospital, No.11 Xizhimen South Street, Beijing 100044, China
}

phase [7]. Furthermore, the presence of this fusion transcript alters the differentiation process and enhances self-renewal of hematopoietic progenitor cells, particularly of the B-lineage [8]. Based on the favorable molecular response to treatment and excellent clinical outcomes, it is believed that this rearrangement has prominent therapeutic significance $[9,10]$, although some recent long-term results have revealed late relapses among patients with ETV6/RUNX1-positive ALL $[11,12]$.

Recently, genome-wide analysis and whole-exome sequencing demonstrated that every ETV6/RUNX1-positive ALL patient could have multiple mutations, underscoring the heterogeneity of this subgroup [13, 14].

(c) The Author(s). 2018 Open Access This article is distributed under the terms of the Creative Commons Attribution 4.0 International License (http://creativecommons.org/licenses/by/4.0/), which permits unrestricted use, distribution, and 
Table 1 Improved BFM protocols at our institution

\begin{tabular}{|c|c|c|}
\hline $\begin{array}{l}\text { Treatment and } \\
\text { medicine }\end{array}$ & Dose & Time \\
\hline \multicolumn{3}{|c|}{ Induction and re-induction therapy } \\
\hline \multicolumn{3}{|l|}{ CODPL } \\
\hline $\begin{array}{l}\text { DEX or } \\
\text { Pred }\end{array}$ & $\begin{array}{l}10 \mathrm{mg} / \mathrm{m}^{2} \text { (maximum: } 10 \mathrm{mg} \text { ) or } \\
60 \mathrm{mg} / \mathrm{m}^{2} \text { (maximum: } 60 \mathrm{mg} \text { ) }\end{array}$ & $\begin{array}{l}\text { d1-28(reduction } \\
\text { in } 1 \text { week) }\end{array}$ \\
\hline VCR & 1.5 mg/m²(maximum:2 mg) & $d 1,8,15,22$ \\
\hline CTX & $1 \mathrm{~g} / \mathrm{m}^{2}$ & d1 \\
\hline $\begin{array}{l}\text { DNR or } \\
\text { IDR }\end{array}$ & $40-60 \mathrm{mg} / \mathrm{m}^{2}$ or $8-10 \mathrm{mg} / \mathrm{m}^{2}$ & $\mathrm{~d} 1,8$ \\
\hline L-asp & $10,000 \mathrm{U} / \mathrm{m}^{2}$ & $\begin{array}{l}d 15,17,19,21,23, \\
25,27,29,31,33\end{array}$ \\
\hline \multicolumn{3}{|c|}{ Consolidation therapy } \\
\hline \multicolumn{3}{|l|}{ HDMTX×2 } \\
\hline HDMTX & $2.5-3.5 \mathrm{~g} / \mathrm{m}^{2}$ & d1, 22 \\
\hline VCR & $1.5 \mathrm{mg} / \mathrm{m}^{2}$ & $d 1,8,15,22$ \\
\hline DNR or IDR & $40-60 \mathrm{mg} / \mathrm{m}^{2}$ or $8-10 \mathrm{mg} / \mathrm{m}^{2}$ & $\mathrm{~d} 8,10$ \\
\hline \multicolumn{3}{|l|}{ HDMTX } \\
\hline HDMTX & $2.5-3.5 \mathrm{~g} / \mathrm{m}^{2}$ & d1 \\
\hline VCR & $1.5 \mathrm{mg} / \mathrm{m}^{2}$ & $\mathrm{~d} 1$ \\
\hline \multicolumn{3}{|l|}{ HDAra-C } \\
\hline HDAra-C & $2 \mathrm{~g} / \mathrm{m}^{2}$ & $d 1-3$ \\
\hline DNR or IDR & $40-60 \mathrm{mg} / \mathrm{m}^{2}$ or $8-10 \mathrm{mg} / \mathrm{m}^{2}$ & $d 2-3$ \\
\hline \multicolumn{3}{|l|}{$\mathrm{IFO}$} \\
\hline $\mathrm{IFO}$ & $1 \mathrm{~g} / \mathrm{m}^{2}$ & $d 1-5$ \\
\hline VP-16 & $100 \mathrm{mg} / \mathrm{m}^{2}$ & $d 3-5$ \\
\hline VCR & $1.5 \mathrm{mg} / \mathrm{m}^{2}$ & d1 \\
\hline \multicolumn{3}{|c|}{ Maintenance therapy } \\
\hline $6-M P$ & $50 \mathrm{mg} / \mathrm{m}^{2}$ & once a day \\
\hline MTX & $20 \mathrm{mg} / \mathrm{m}^{2}$ & once a week \\
\hline
\end{tabular}

$D E X$ dexamethasone, Pred prednisone, $V C R$ vincristine, CTX cyclophosphamide, DNR daunomycin, IDR idarubicin, L-asp native Escherichia coli L- asparaginase, HDMTX high dose methotrexate, HDAra-C high dose cytarabine, IFO ifosfamide, VP-16 etoposide, 6-MP mercaptopurine
Moreover, this genetic heterogeneity may influence overall treatment response and survival. In this evaluation, we reviewed the outcomes of children with ETV6/ RUNX1-positive ALL treated at our institution and attempted to identify significant prognostic factors with regards to survival.

\section{Methods}

\section{Patients and treatment}

Seventy seven patients diagnosed with ETV6/RUNX1-positive ALL from January 2005 to December 2015 at the Department of Pediatrics were included in the initial study cohort. The diagnosis and classification of ALL were based on immunophenotyping, cytogenetics, and molecular abnormality. The diagnosis of ETV6/RUNX1 rearrangement was established by real-time quantitative polymerase chain reaction (RQ-PCR), as the detection rate of this translocation using conventional karyotyping (G-banding) analysis is less than $0.05 \%$ [15]. A bone marrow study was conducted every 2-3 months for MRD detection using RQ-PCR during the first 3 years from diagnosis. Thereafter, they were detected every half year for a total of 5 years.

All the patients were treated according to the ALL-B protocol deriving from the improved Berlin-Frankfurt-Münster (BFM) protocol (Table 1 and Fig. 1). In brief, patients received a five-drug remission induction followed by the consolidation treatment and maintenance therapy. During the consolidation treatment, there were two courses of 4-week re-induction therapy. Besides, patients also received triple intrathecal therapy (TIT) treatments for a total of 20-22 doses to avoid central nervous system leukemia (CNSL). The whole treatment course lasts 3 years.

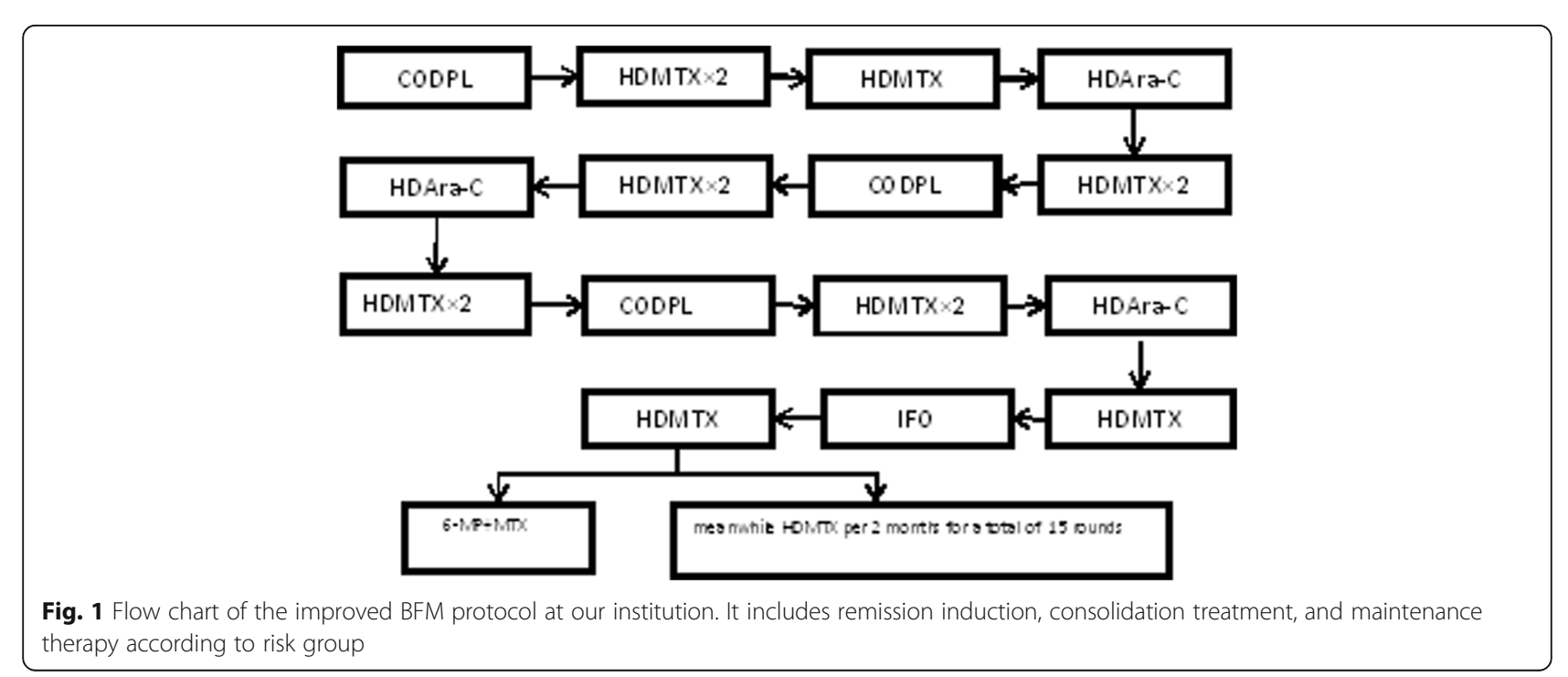


Risk stratification was further refined by including MRD measurements at the end of remission induction therapy (cut-off, $10^{-3}$ ) regardless of age and leukocyte count. The dose and intensity of anthracyclines as well as high-dose methotrexate differed by risk group.

Informed consent was obtained from the parent or guardian and assent obtained from the patient when appropriate.

\section{Statistical analysis}

Overall survival (OS) was measured from the time of diagnosis to the date of last follow-up or death from any cause. Disease-free survival (DFS) was calculated from complete remission (CR) to the first hematologic relapse. Finally, event-free survival (EFS) was defined as the time from diagnosis of ALL to the last follow-up in CR or the first event that included a molecular relapse (recurrence of MRD), secondary malignancy, or death. Clinical analysis and comparison was estimated according to the method of descriptive analysis and Chi-square test. Kaplan-Meier survival curve and Log-rank test was used for survival analysis; $C O X$ regression analysis was performed in multivariate analysis. A statistically significant difference was set to a $p$ value $<0.05$.

\section{Results}

\section{Patient characteristics}

Some of the clinical characteristics are presented in Table 2. According to the immunophenotype, all 77 patients were diagnosed as B-precursor ALL. No $t$ $(12 ; 21)$ expression was detected in 66 patients via conventional G-banding analysis. Cytogenetic abnormalities other than the cryptic ETV6/RUNX1 rearrangement were identified by G-banding analysis. The most frequent structural aberrations analyzed by G-banding included those in chromosomes 12,6,21 and 9. Structural abnormalities involving chromosomes 12 and 6 were found in 7 and 9 patients, respectively and further characterized with addition of $12 \mathrm{q}$ and deletion of $6 \mathrm{q}$. Trisomy for chromosomes 21 was detected in three patients, while loss of chromosome 21 was detected in another 3 patients.

\section{Early treatment response}

All 77 patients achieved CR at the end of remission induction chemotherapy (Day +33$)$. However, the level of MRD was not completely negative as analyzed by RQ-PCR techniques. As a result, 29 MRD-positive cases $(n=71,40.8 \%)$ were detected ranging from $0.0049 \%$ $14.5 \%$ using RQ-PCR.

\section{Late treatment response}

The median follow-up for this subgroup was 71 months (range 19-154 months). The probability of 5-year OS,
Table 2 Clinical characteristics of patients with initial ETV6RUNX1-positive ALL

\begin{tabular}{|c|c|c|c|}
\hline Clinical features & number (ratio) & range & median \\
\hline \multicolumn{4}{|l|}{ Gender } \\
\hline male & $48(62.3 \%)$ & & \\
\hline female & 29(37.7\%) & & \\
\hline Age (years) & & & 4 \\
\hline$<1$ & 0 & & \\
\hline $1 \sim 6$ & $59(76.6 \%)$ & & \\
\hline $6 \sim 10$ & $12(15.6 \%)$ & & \\
\hline$>10$ & $6(7.8 \%)$ & & \\
\hline WBC $\left(\times 10^{9} / L\right)$ & & & 11 \\
\hline$<20$ & $54(70.1 \%)$ & $0.4 \sim 20$ & 5.3 \\
\hline $20 \sim 50$ & $12(15.6 \%)$ & $21 \sim 48$ & 33 \\
\hline$>50$ & $11(14.3 \%)$ & $55 \sim 145$ & 75 \\
\hline $\operatorname{PLT}\left(\times 10^{9} / \mathrm{L}\right)$ & & & 48 \\
\hline$<100$ & $52(67.5 \%)$ & $3 \sim 95$ & 36.5 \\
\hline$\geq 100$ & $25(32.5 \%)$ & $102 \sim 457$ & 150 \\
\hline \multicolumn{4}{|l|}{ Immunophenotype } \\
\hline Common-B & $60(77.9 \%)$ & & \\
\hline Pre-B & $17(22.1 \%)$ & & \\
\hline Chromosome & $66(85.7 \%)$ & & \\
\hline hyperdiploidy & $7(10.6 \%)$ & & \\
\hline hypodiploidy & $6(9.1 \%)$ & & \\
\hline normal karyotype & $45(68.2 \%)$ & & \\
\hline pseudodiploidy & $22(33.3 \%)$ & & \\
\hline ETV6-RUNX1/ABL (\%) & $77(100 \%)$ & $20.9 \sim 789.1$ & 240.78 \\
\hline MRD on Day + 33(\%) & $71(92.2 \%)$ & & \\
\hline$\geq 10^{-2}$ & $6(8.5 \%)$ & $1.7 \sim 14.5$ & 2.25 \\
\hline $10^{-2} \sim 10^{-3}$ & $7(9.9 \%)$ & $0.1 \sim 0.67$ & 0.2 \\
\hline $10^{-3} \sim 10^{-4}$ & 14(19.7\%) & $0.019 \sim 0.091$ & 0.03 \\
\hline $10^{-4} \sim 10^{-5}$ & $2(2.8 \%)$ & $0.0049 \sim 0.0062$ & 0.0055 \\
\hline negative & $42(59.2 \%)$ & 0 & 0 \\
\hline
\end{tabular}

WBC white blood count, $P L T$ platelets, MRD minimal residual disease detected by $R Q-P C R$

DFS and EFS were reported to be $97 \pm 2 \%, 96 \pm 3 \%$, and $90 \pm 3 \%$, respectively (Fig. 2). Two patients subsequently developed hematological relapse (presence of leukemic blasts $>5 \%$ in $\mathrm{BM}$ ) at a median of 42 months from diagnosis (33 and 51 months, respectively). A 5-year cumulative incidence of relapse was calculated as $2.1 \%$.

\section{Survival analysis}

Univariate analysis of prognostic factors for EFS revealed that WBC $>50 \times 10^{9} / \mathrm{L}$ and the MRD $\geq 10^{-3}$ on Day +33 had a significant impact, with the presence of other factors predicting worse outcome (Table 3). Multivariate 

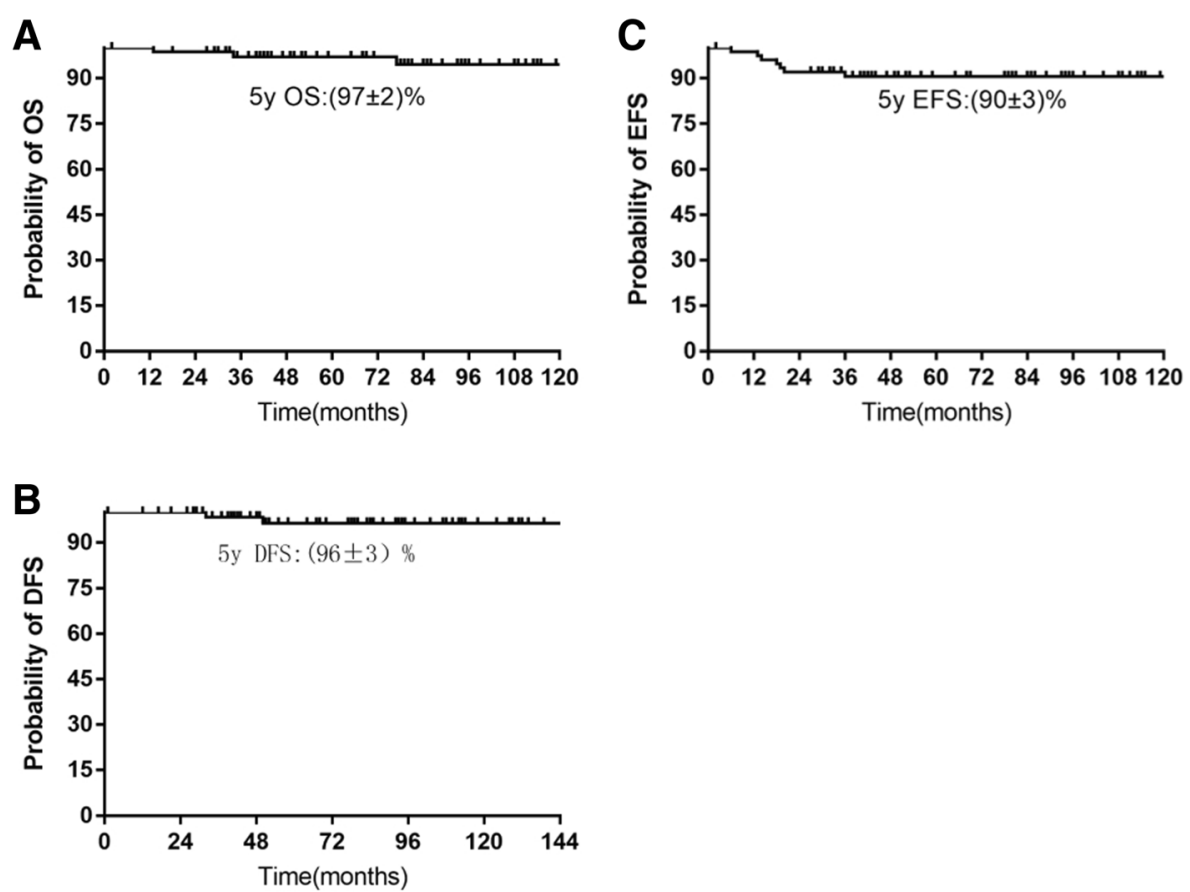

Fig. 2 Kaplan-Meier estimates of OS (a), DFS (b) and EFS (c) in ETV6/RUNX1 pediatric ALL patients by study. Rates at 5 years are reported as means \pm standard errors. The probability of 5 -year OS, DFS and EFS were reported to be $(97 \pm 2) \%$, (96 \pm 3$) \%$, and $(90 \pm 3) \%$, respectively

analysis revealed that only MRD $\geq 10^{-3}$ on Day +33 was an independent risk factor for EFS (Table 4).

\section{Discussion}

Here, we report the clinical features, response to chemotherapy, prognostic factors and outcome for ETV6/ RUNX1-positive ALL in Chinese children treated according to the improved BFM protocol at our institution.

Among variables that influenced EFS, we found MRD as detected by RQ-PCR for the ETV6/RUNX1 transcript on Day +33 as well as WBC $>50 \times 10^{9} / \mathrm{L}$ at the time of

Table 3 Univariate analyses of factors influencing EFS

\begin{tabular}{llll}
\hline Factor & Patient & Event & $P$ \\
\hline Age (years) & & & 0.351 \\
$\quad<5$ & 51 & 3 & \\
$\quad>5$ & 26 & 3 & 0.045 \\
$\begin{array}{l}\text { WBC }\left(\times 10^{9} / L\right) \\
<50\end{array}$ & 66 & 2 & \\
$>50$ & 11 & 4 & 0.025 \\
MRD on Day +33 & & & \\
$<10^{-3}$ & 59 & 1 & 0.864 \\
$\quad \geq 10^{-3}$ & 13 & 5 & \\
MRD on Day +90 & & & \\
$\quad$ negative & 66 & 5 & \\
positive & 11 & 1 & \\
\hline
\end{tabular}

diagnosis to be significant. Although leukocyte count, but not age, was found to be a prognostic factor in our study, many reports have suggested that National Cancer Institute (NCI)/Rome risk group status based on age and initial WBC count should be considered when treating ETV6/RUNX1-positive patients [16, 17]. However, according to our multivariate analysis only MRD on Day +33 had a significant negative impact on EFS. Multiple available data has been established to determine the MRD level at the end of induction therapy in order to evaluate the response to chemotherapy [18]. In our cohort, the cut-off level of MRD at the end of induction therapy was $10^{-3}$. In order to determine if a lower MRD level at such a time better defines poor prognosis, a greater number of patients need to be analyzed. In contrast to the prognostic relevance of MRD on Day + 33, lower level MRD on Day +90 among fewer positive

Table 4 Multivariate analyses of factors influencing EFS

\begin{tabular}{|c|c|c|}
\hline Factor & Hazard ratio $(95 \%$ Cl) & P \\
\hline MRD on Day +33 & & 0.034 \\
\hline$<10^{-3}$ & 1 & \\
\hline$\geq 10^{-3}$ & $2.416(1.480 \sim 12.169)$ & \\
\hline $\mathrm{WBC}\left(\times 10^{9} / \mathrm{L}\right)$ & & 0.285 \\
\hline$>50$ & 1 & \\
\hline$<50$ & $0.173(0.034 \sim 0.877)$ & \\
\hline
\end{tabular}

Cl confidence interval 
patients failed to show significance consistent with previous studies $[18,19]$.

According to our results, the treatment outcomes for this genetic subtype at our institution were excellent with OS and DFS rates greater than $90 \%$, though $40 \%$ of the patients had detectable MRD at the end of induction therapy. The favorable outcome may be attributed to the assessment of risk stratification and differences in the intensities of chemotherapy in our treatment protocol. At our institution, patients with higher MRD levels were treated with more intensive chemotherapy regimens (relatively high dose shown in Table 1), together with a reduced treatment interval to eliminate the negative prognostic impact. Many studies have proven this opinion. For instance, DFCI ALL Consortium protocols before 1995 used a more rigorous criteria at lower risk $[6,20]$. In fact, the outcome was superior and findings from other studies have supported this result indirectly $[3,6,21]$. Besides, previous studies have demonstrated that ETV6/RUNX1-positive lymphoblasts were exquisitely sensitive to high-dose methotrexate and L-asparaginase in vitro [22, 23]. Patients with ETV6/ $R U N X 1$ fusion transcript may benefit from the intensive L-asparaginase and high-dose methotrexate employed in our protocol. A longer treatment course may also be one of the most important factors in determining prognosis, as the majority of relapses occur off-therapy [11], and even after $10-20$ years [24]. These observations were consistent with Total Therapy study XV at St Jude Children's Research Hospital [10]. Moreover, it is worth mentioning that there were no serious toxic complications, secondary malignancies and treatment-related mortality in our cohorts. But a longer follow-up time is needed to draw the correct conclusion.

Unfortunately, we were unable to explore $I g H / T C R$ rearrangements or sequence the ETV6/RUNX1 genome to have a better understanding of the two treatment failures.

In conclusion, our studies clearly indicate an excellent prognosis for ETV6/RUNX1-positive ALL patients. However, larger, prospective clinical trials will be needed to confirm whether ETV6/RUNX1 can be a completely independent prognostic factor.

\section{Conclusions}

In summary, our ETV6/RUNX1-positive ALL cohort had an excellent prognosis. Significant MRD at the end of remission induction chemotherapy adversely affected EFS. Larger scale studies will be necessary to confirm the factors that characterize a potential subset with poor outcome, and to improve the survival of this subtype.

\section{Abbreviations}

ALL: Acute lymphoblastic leukemia; CNSL: Central nervous system leukemia; CR: Complete remission; DFS: Disease-free survival; EFS: Event-free survival;
MRD: Minimal residual disease; OS: Overall survival; RQ-PCR: Real-time quantitative polymerase chain reaction

Funding

This work was supported by the National Natural Science Foundation of China (No.81641007).

\section{Availability of data and materials}

These could be seen from the tables and figures. The detailed datasets are available from the corresponding author on reasonable request.

\section{Authors' contributions}

YW contributed to acquisition and analysis of the data, statistical analysis, manuscript preparation and interpretation; $\mathrm{HZ}$ and LZ contributed to the concepts and design of the study, literature search. All authors provided critical review of the manuscript and approval of the final version of the manuscript.All listed authors meet the criteria for authorship set forth by the International Committee for Medical Journal Editors. All authors read and approved the final manuscript.

\section{Ethics approval and consent to participate}

This study was approved by the ethics committee of our intistuion. This manuscript is not under simultaneous consideration by any other publication.

Informed consent was obtained from the parent or guardian and assent obtained from the patient when appropriate.

\section{Consent for publication}

Informed consent was obtained from the parent or guardian and assent obtained from the patient when appropriate.

\section{Competing interests}

The authors declare that they have no competing interest.

\section{Publisher's Note}

Springer Nature remains neutral with regard to jurisdictional claims in published maps and institutional affiliations.

Received: 13 February 2018 Accepted: 12 August 2018

Published online: 16 August 2018

\section{References}

1. Pui $\mathrm{CH}$, Evans WE. Treatment of acute lymphoblastic leukemia [J]. N Engl J Med. 2006;354(2):166-78

2. Stanulla M, Schrappe M. Treatment of childhood acute lymphoblastic leukemia [J]. Semin Hematol. 2009;46(1):52-63.

3. Shurtleff SA, Buijs A, Behm FG, Rubnitz JE, Raimondi SC, Hancock ML, et al. TEL/AML1 fusion resulting from a cryptic $t(12 ; 21)$ is the most common genetic lesion in pediatric ALL and defines a subgroup of patients with an excellent prognosis [J]. Leukemia. 1995;9(12):1985-9.

4. Romana SP, Mauchauffé M, Le Coniat M, Chumakov I, Le Paslier D, Berger R, et al. The $\mathrm{t}(12 ; 21)$ of acute lymphoblastic leukemia results in a tel-AML1 gene fusion [J]. Blood. 1995;85(12):3662-70.

5. Borkhardt A, Cazzaniga G, Viehmann S, Valsecchi MG, Ludwig WD, Burci L, et al. Incidence and clinical relevance of TEL/AML1 fusion genes in children with acute lymphoblastic leukemia enrolled in the German and Italian multicenter therapy trials. Associazione Italiana Ematologia Oncologia Pediatrica and the berlin-Frankfurt-Munster study group [J]. Blood. 1997; 90(2):571-7

6. McLean TW, Ringold S, Neuberg D, Stegmaier K, Tantravahi R, Ritz J, et al. TEL/AML-1 dimerizes and is associated with a favorable outcome in childhood acute lymphoblastic leukemia [J]. Blood. 1996;88(11):4252-8.

7. Wiemels JL, Cazzaniga G, Daniotti M, Eden OB, Addison GM, Masera G, et al. Prenatal origin of acute lymphoblastic leukaemia in children [J]. Lancet. 1999:354(9189):1449-503.

8. Morrow M, Horton S, Kioussis D, Brady HJ, Williams O. TEL-AML1 promotes development of specific hematopoietic lineages consistent with preleukemic activity [J]. Blood. 2004;103(10):3890-6.

9. Enshaei A, Schwab CJ, Konn ZJ, Mitchell CD, Kinsey SE, Wade R, et al. Longterm follow-up of ETV6-RUNX1 ALL reveals that NCI risk, rather than 
secondary genetic abnormalities, is the key risk factor [J]. Leukemia. 2013; 27(11):2256-9.

10. Bhojwani D, Pei D, Sandlund JT, Jeha S, Ribeiro RC, Rubnitz JE, et al. ETV6RUNX1-positive childhood acute lymphoblastic leukemia: improved outcome with contemporary therapy [J]. Leukemia. 2012;26:265-70.

11. Forestier E, Heyman M, Andersen MK, Autio K, Blennow E, Borgstrom G, et al. Outcome of ETV6/RUNX1-positive childhood acute lymphoblastic leukaemia in the NOPHO-ALL-1992 protocol: frequent late relapses but good overall survival [J]. Br J Haematol. 2008;140(6):665-72.

12. Gandemer V, Chevret S, Petit A, Vermylen C, Leblanc T, Michel G, et al. Excellent prognosis of late relapses of ETV6/RUNX1-positive childhood acute lymphoblastic leukemia: lessons from the FRALLE 93 protocol [J]. Haematologica. 2012;97(11):1743-50.

13. Borst L, Wesolowska A, Joshi T, Borup R, Nielsen FC, Andersen MK, et al. Genome-wide analysis of cytogenetic aberrations in ETV6/RUNX1-positive childhood acute lymphoblastic leukaemia [J]. Br J Haematol. 2012;157(4): 476-82.

14. Lilljebjörn H, Rissler M, Lassen C, Heldrup J, Behrendtz M, Mitelman F, et al. Whole-exome sequencing of pediatric acute lymphoblastic leukemia [J]. Leukemia. 2012;26(7):1602-7.

15. Raimondi SC. Current status of cytogenetic research in childhood acute lymphoblastic leukemia [J]. Blood. 1993;81(9):2237-51.

16. Enshaei A, Schwab CJ, Konn ZJ, Mitchell CD, Kinsey SE, Wade R, et al. Longterm follow-up of ETV6-RUNX1 ALL reveals that NCI risk, rather than secondary genetic abnormalities,is the key risk factor []]. Leukemia. 2013; 27(11):2256-9.

17. Borowitz MJ, Devidas M, Hunger SP, Bowman WP, Carroll AJ, Carroll WL, et al. Clinical significance of minimal residual disease in childhood acute lymphoblastic leukemia and its relationship to other prognostic factors: a Children's oncology group study [J]. Blood. 2008;111(12):5477-85.

18. Madzo J, Zuna J, Muzíková K, Poon WM, Vattikuti S, Cardoso A, et al. Slower molecular response to treatment predicts poor outcome in patients with TEL/AML1 positive acute lymphoblastic leukemia: prospective real-time quantitative reverse transcriptase-polymerase chain reaction study [J]. Cancer. 2003:97(1):105-13.

19. Lee JW, Kim SK, Jang PS, Chung NG, Jeong DC, Kim M, et al. Outcome and prognostic factors for ETV6/RUNX1 positive pediatric acute lymphoblastic leukemia treated at a single institution in Korea [J]. Cancer Res Treat. 2017; 49(2):446-53.

20. Loh ML, Silverman LB, Young ML, Neuberg D, Golub TR, Sallan SE, et al. Incidence of TEL/AML1 fusion in children with relapsed acute lymphoblastic leukemia [J]. Blood. 1998;92(12):4792-7.

21. Takahashi Y, Horibe K, Kiyoi H, Miyashita Y, Fukuda M, Mori H, et al. Prognostic significance of TEL/AML1 fusion transcript in childhood Bprecursor acute lymphoblastic leukemia [J]. J Pediatr Hematol Oncol. 1998; 20(3):190-5.

22. Krishna Narla R, Navara C, Sarquis M, Uckun FM. Chemosensitivity of telaml1 fusion transcript-positive acute lymphoblastic leukemia cells [J]. Leuk Lymphoma. 2001;41(5-6):615-23.

23. Ramakers-van Woerden NL, Pieters R, Loonen AH, Hubeek I, van Drunen E, Beverloo HB, et al. TEL/AML1 gene fusion is related to in vitro drug sensitivity for L-asparaginase in childhood acute lymphoblastic leukemia [J]. Blood. 2000;96(3):1094-9.

24. Chow CD, Dalla-Pozza L, Gottlieb DJ, Hertzberg MS. Two cases of very late relapsing ALL carrying the TEL: AML1 fusion gene [J]. Leukemia. 1999;13(11): $1893-4$

Ready to submit your research? Choose BMC and benefit from:

- fast, convenient online submission

- thorough peer review by experienced researchers in your field

- rapid publication on acceptance

- support for research data, including large and complex data types

- gold Open Access which fosters wider collaboration and increased citations

- maximum visibility for your research: over $100 \mathrm{M}$ website views per year

At $\mathrm{BMC}$, research is always in progress.

Learn more biomedcentral.com/submissions 